\title{
Erratum
}

Due to an error of the authors, F. Curro was not mentioned as co-author of the paper:

\section{Ophthalmological and Pharmacological Studies after Administration of Clonidine in Rats}

Arch. Toxicol. 41, 89-98 (1978)

The order of authors' names is corrected as follows:

I. Weisse', W. Hoefke ${ }^{2}$, S. Greenberg ${ }^{3}$, F. Curro ${ }^{4}$, W. Gaida ${ }^{2}$, H. Stötzer ${ }^{1}$, and $\mathrm{H}$. Kreuzer ${ }^{1}$

1 Departments of Experimental Pathology and Toxicology and

2 Pharmacology C. H. Boehringer Sohn,

D-6507 Ingelheim/Rhein, Federal Republic of Germany

${ }^{3}$ Department of Pharmacology, College of Medicine, University of South Alabama, Mobile, Alabama, USA

4 Department of Pharmacology, School of Dentistry, Fairleigh Dickinson University, Hackensack, New Jersey, USA 